\title{
The Research Centre for Translation (RCT) The Chinese University of Hong Kong
}

\author{
Lawrence Wang-chi WONG*
}

The Research Centre for Translation (RCT), established in 1971, is a research unit at the Institute of Chinese Studies (ICS), The Chinese University of Hong Kong (CUHK). It is Hong Kong's first research centre dedicated solely to the development of Translation and Translation Studies, and one of the oldest translation research centres in Asia and the world.

The Centre was the brainchild of the late $\mathrm{Mr}$ Stephen C. Soong, named then as the Centre for Translation Projects, with the aim of promoting Chinese literature internationally through high-quality English translation. The biannual journal Renditions was launched in 1973, which publishes English translations of fine Chinese literary work from the classical to the contemporary. Series Renditions Books and Renditions Paperbacks were launched in 1976 and 1986 respectively, earning the praise of transla-

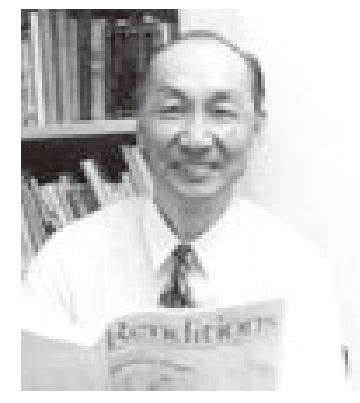

Stephen C. Soong tion and academic circles around the globe. The Centre officially changed its name to Research Centre for Translation in 1983, and began to promote Translation Studies as a serious academic discipline by regularly holding scholarly events, rapidly establishing itself as a key translation research unit in China and Asia.

* Lawrence Wang-chi WONG 王宏志 is Chairman and Professor of Humanities at the Department of Translation, and the Director of the Research Centre for Translation, The Chinese University of Hong Kong 


\section{RCT Logo

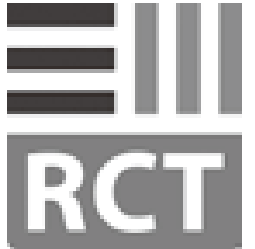

The Research Centre for Translation started to use its new logo in 2011. Shaped like a traditional seal, the Centre's acronym 'RCT' is carved into the vermilion base, with three horizontal strips representing the standard form of printed English and three vertical lines corresponding to that of Chinese. It is a seal symbolizing interchange between

English and Chinese.

\section{The Centre Director}

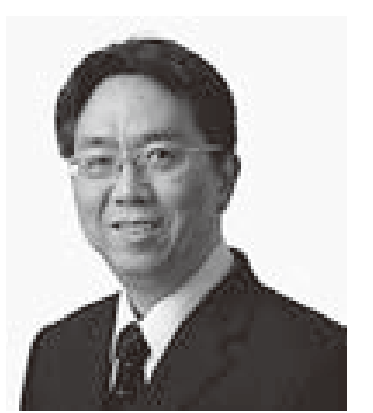

Professor Lawrence Wang-chi Wong is currently Chairman and Professor of Humanities at the Department of Translation, and the Director of the Research Centre for Translation, The Chinese University of Hong Kong. He was Associate Dean (Research) and Director of Research Institute of Humanities, and Director of the Centre for Hong Kong Cultural Studies, CUHK. He was Associate Dean (Research) and Director of Research Institute of Humanities, and Director of the Centre for Hong Kong Cultural Studies, CUHK. He was also the founding Dean of the School of Humanities and Social Sciences as well as the founding Dean of the College of Humanities, Arts, and Social Sciences, the founding director of the Centre for Liberal Arts and Social Sciences, Nanyang Technological University, Singapore. His research interests are in translation history of China in the early modern and modern period (18th century onwards), modern Chinese literature, and Hong Kong cultural studies. He has so far single-authored 15 books and over 130 academic articles and book chapters in these fields, including Translation and Modern China (2014), Between Translation and Literature (2011), Reinterpreting Xin Da Ya: Translation Studies of The Twentieth Century China (1999 \& 2007), Lu Xun and the Left League (1991 \& 2006) and Between Literature and Politics (1994). He is Executive Editor of Renditions and Chief Editor of Journal of Translation Studies and Studies in Translation History.

Professor Lawrence Wang-chi Wong became the director of the RCT in 2005. 


\section{Chief Editor}

Professor Theodore Huters is professor emeritus of the University of California, Los Angeles, where he taught at the Department of Asian Languages and Cultures. He is a distinguished scholar in modern Chinese literature and Chinese culture. His major publications include Bringing the World Home: Approaching the West in Late Qing and Early Republican China, and China's New Order: Society, Politics, and Economy in Transition.

Professor Huters joined the RCT as the Chief Editor of Renditions in 2010.

\section{Honorary Research Staff and Visiting Scholars}

The RCT started appointing honorary research posts in 2009 with the aim of enhancing international communication and cooperation and promoting translation research. Currently eight distinguished scholars from mainland China, Taiwan, Singapore, Canada and the UK have taken the positions of Honorary Senior Research Fellow, Honorary Research Fellow or Honorary Research Associate and actively participate in the Centre's various research programmes and activities.

The RCT also regularly invites renowned scholars or young researchers who are engaged in translation research or interested in participating in conferences and seminars to visit the Centre as Visiting Scholars.

\section{Centre Activities}

The Centre has two main branches of activities__ Literary Translation and Translation Studies.

\section{Literary Translation}

Since its establishment, the RCT has devoted itself to promoting Chinese literature internationally through quality translation; this remains one of the RCT's primary objectives. The Centre's flagship journal Renditions is a biannual journal dedicated to publishing English translations of fine Chinese literary work, with 82 issues to date, and is recognized internationally as one of the most important of its kind. The series Renditions Books and Renditions Paperbacks were launched to meet the demand of different readerships, the former in hardcover is of a more academic focus with 19 titles to date, and the latter, in paperback intended for a more general readership, has published 30 titles. Renditions CD-ROM and PDA series followed in 2002.

The Centre has launched a new online shopping system, the RCT 


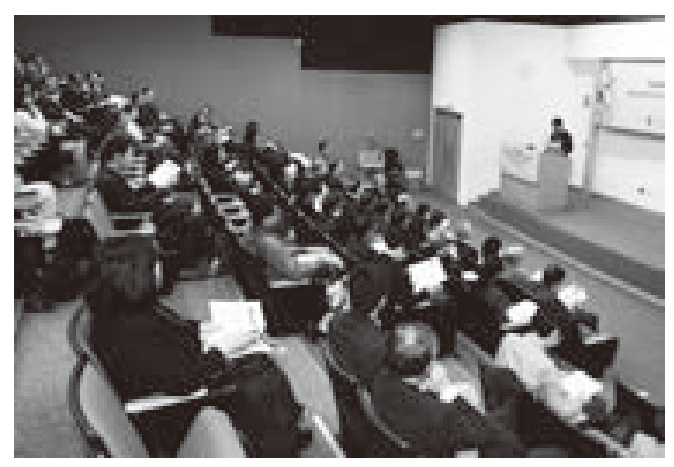

The Fourth International Conference on Asian Translation Traditions (Hong Kong)

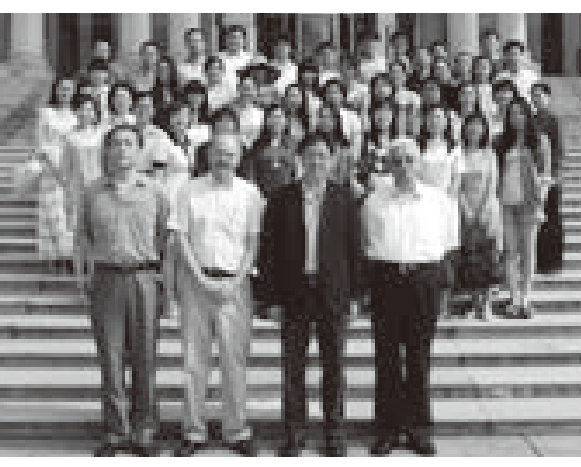

Summer School (Shanghai, 2011)

Bookstore (eshop.rct.cuhk.edu.hk/), where all publications by the centre are now available for ordering online.

\section{Translation Studies}

Translation Studies has been gradually gaining importance as an academic discipline since the 1980s. The RCT is increasingly focusing its efforts in advancing innovative translation research, and emphasizes particularly but not exclusively on historical and cultural contexts, with topics pertaining to Hong Kong, China and the rest of Asia.

The Centre regularly holds academic events, including seminars, conferences, workshops, awards and summer schools for graduate students, and regularly publishes journals and book series. It collaborates closely with universities and research institutes in mainland China, Taiwan, and also those in other parts of the world.

\section{Stephen C. Soong Translation Studies Memorial Awards}

To commemorate Mr Stephen C. Soong's contributions in the promotion of translation education and research, the RCT set up the Stephen C. Soong Translation Studies Memorial Awards in 1997 with a generous donation from the Soong family. The Awards give recognition to academics that have made contributions of original research in Chinese Translation Studies. Each winner will be awarded with a prize and certificate.

\section{International Conferences}

The Centre regularly holds international conferences and seminars, including 'The Fourth International Conference on Asian Translation Traditions' (2010), the first 'Sinologists as Translators in the 17-19th Century Conference' (2011) and 'Translation and Modernization in East Asia in the 19th and Early 20th Century Conference' (2013), that attracted the attention 
and won praise from international academic circles.

\section{Workshops}

The Centre frequently holds workshops, sharing the latest developments in the Centre's many research areas, such as the 2012 'Translation and Colonial Rule in Taiwan' Workshop, and the 'A Database for Chinese Translation History' Workshop in 2013.

\section{Nurturing Young Talents}

The RCT started the 'Young Researchers' Conference' in 2004 and the 'Summer School on Chinese Translation History' in 2009, both biennial events with the aim of nurturing the finest young talents in the field. The first event invites distinguished scholars to give detailed feedback to young researchers after they have presented their papers at the conference, and the latter event gives young researchers the chance to listen to lectures by scholars on the latest research methodologies in translation history, enhancing the development of translation studies as a serious academic discipline. The 'Summer School on Chinese Translation History' is held in collaboration with prominent universities in mainland China or Taiwan.

\section{RCT Research Programme Fund}

The Research Centre for Translation set up the RCT Research Programme Fund in 2010 to support research programmes/projects in translation studies. At the moment, projects supported by the RCT Research Programme Fund include:

- Sinologists as Translators in the 17-19th Century

- Translation and Modernization in East Asia

- Translation and Colonial Rule in Asia

- A Database for Chinese Translation History

A grant of up to HK\$100,000 a year will be provided to each project to support research, workshops, conferences, and publishing.

\section{Publications on Translation Studies}

- Translation Studies Research, a book series first published in 1998, with 6 titles to date.

- Fanyishi yanjiu 翻譯史研究 [Studies in Translation History], an annual academic journal launched in 2011 published and distributed by Fudan University Press, is currently the only academic journal dedicated to publishing articles on Chinese Translation history.

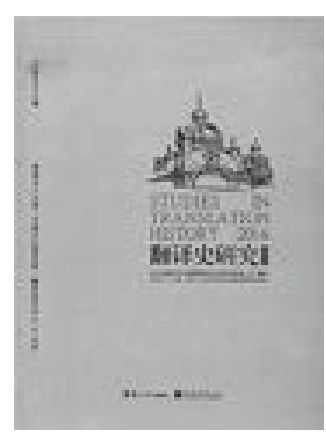


- Fanyishi Yanjiu Luncong 翻譯史研究論叢 [Studies in Translation History], launched in 2012 published and distributed by Chinese University Press, is a Chinese book series devoted to the case study of Chinese translation history.

- Asian Translation Traditions, scheduled for launch in 2014 to be published and distributed by Chinese University Press, is a English book series of case studies or essay collections on translation traditions of Asian countries and areas.

All published articles in Fanyishi yanjiu, Fanyishi Yanjiu Luncong and Asian Translation Traditions are approved by the academic committee and go through a double blind external review.

\section{Friends of RCT}

The RCT contact list has now almost 5,000 people, and we send by email information on the latest events held by the RCT. In order to promote the exchange, share and discussion of the latest developments on translation studies, the RCT has planned the electronic platform 'Friends of the RCT', which will be officially launched in a year's time.
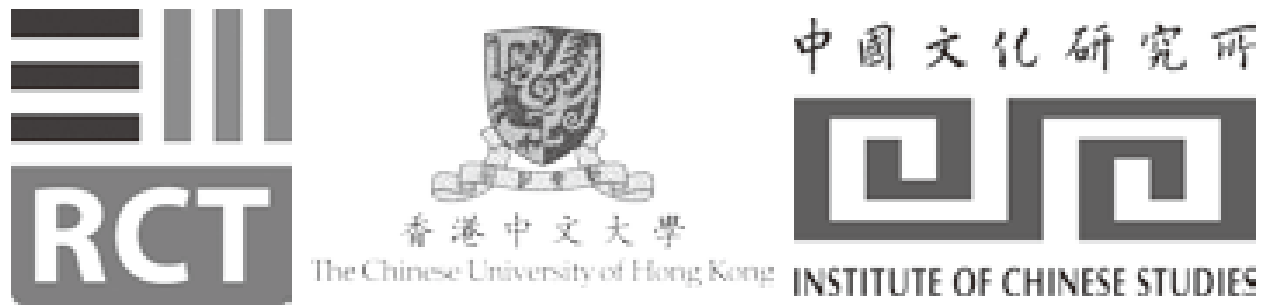